\title{
Matéria seca de plantas de cobertura, produção de cebola e atributos químicos do solo em sistema plantio direto agroecológico
}

\author{
Dry matter of cover crops, onion yield and soil chemical attributes in agroecological no-tillage system
}

\author{
Monique Souza $^{\mathrm{I}^{*}}$ Jucinei José Comin $^{\mathrm{I}}$ Eduardo Sixto Leguizamón ${ }^{\mathrm{II}}$ Claudinei Kurtz ${ }^{\mathrm{III}}$ \\ Gustavo Brunetto $^{\mathrm{I}}$ Vilmar Müller Júnior $^{\mathrm{IV}}$ Bárbara Ventura $^{\mathrm{IV}}$ Ana Paula Camargo ${ }^{\mathrm{I}}$
}

RESUMO

O cultivo e a deposição de resíduos de plantas de cobertura em sistema plantio direto podem afetar os atributos químicos do solo e a produção de cebola. O trabalho objetivou avaliar a interferência do cultivo de plantas de cobertura sobre a produção de cebola e sobre os atributos químicos do solo em sistema plantio direto (SPD) agroecológico. O experimento foi conduzido na EPAGRI, em Ituporanga (SC), em um Cambissolo Húmico, nas safras de 2010 e 2011. Em abril, foram implantados os tratamentos: testemunha com vegetação espontânea (T1); cevada (2010)/aveia-preta (2011) (T2); centeio (T3); nabo-forrageiro (T4); centeio + nabo-forrageiro (T5); e cevada (2010)/aveia-preta (2011) + nabo-forrageiro (T6). Aos 60, 80 e 95 dias após a semeadura (DAS) das espécies de inverno, coletou-se a parte aérea das plantas e determinouse a produção de matéria seca por hectare. Em julho, foram transplantadas mudas de cebola e, em novembro, avaliou-se a produção. Após o acamamento das plantas de cobertura de inverno e a colheita da cebola, foi coletado solo na camada de $0-10 \mathrm{~cm}$ e submetido à análise de atributos químicos. O cultivo e a deposição dos resíduos de matéria seca das espécies de plantas de cobertura em SPD contribuíram para o aumento e a manutenção da produção total de cebola ao longo dos anos. Os atributos químicos do solo, com exceção do K trocável, $P$ disponível e valores de saturação da $C T C_{p H 7,0}$ por bases não foram afetados pelo cultivo de plantas de cobertura.

Palavras-chave: adubação verde, disponibilidade de nutrientes, Allium cepa $L$.

\begin{abstract}
The cultivation and deposition of waste from cover crops in no-tillage can affect soil chemical attributes and onion yield. The aim of this study was to evaluate the dry matter yield of plant species from winter cover crops, onion yield and chemical attributes of soil in agroecological no-tillage system. The experiment was carried out at EPAGRI Experimental Station in Ituporanga (SC) under Humic Haplumbrept in the agricultural years of 2010 and 2011. The following treatments was implanted in April: weed vegetation (T1), Hordeum vulgare L. (2010)/Avena strigosa L. (2011) (T2), Secale cereale L. (T3), Raphanus sativus L. (T4), Secale cereale L + Raphanus sativus L. (T5) e Hordeum vulgare L. (2010)/Avena strigosa L. (2011) + Raphanus sativus L. (T6). At 60, 80 and 95 days after sowing (DAS) of winter species, the cover crops were collected to determine the dry matter yield. In July the onion seedlings were transplanted and in November the yield was evaluated. After the rolling of winter cover crops and after onion harvest, soil was collected at $0-10 \mathrm{~cm}$ for the evaluation of chemical attributes. The cultivation and deposition of waste from cover crops in no-tillage contributed to the growth and maintenance of the total production of onion over the years. The soil chemical attributes in $0-10 \mathrm{~cm}$ layer, with the exception of exchangeable $K$, available $P$ and $C T C_{p H 7,0}$ saturation values for bases, were not affected by cover crops cultivation and deposition of waste.
\end{abstract}

Key words: green manuring, nutrient availability, Allium cepa $L$.

IPrograma de Pós-graduação em Agroecossistemas (PPGA), Departamento de Engenharia Rural (ENR), Centro de Ciências Agrárias (CCA), Universidade Federal de Santa Catarina (UFSC), Av. Admar Gonzaga, 1346, 88034-000, Florianópolis, SC, Brasil. E-mail: monique_souzaaa@yahoo.com.br. *Autor para correspondência.

IIDepartamento de Sistemas de Produção Vegetal, Universidade Nacional de Rosário (UNR), Argentina.

IIIEmpresa de Pesquisa Agropecuária e Extensão Rural de Santa Catarina (EPAGRI), Estação Experimental de Ituporanga, Ituporanga, SC, Brasil.

${ }^{\mathrm{IV}}$ Curso de Graduação em Agronomia, CCA, UFSC, Florianópolis, SC, Brasil. 


\section{INTRODUÇÃO}

Os solos cultivados com cebola em Santa Catarina (SC), como aqueles encontrados no Alto Vale do Itajaí, encontram-se intensamente degradados, devido ao uso intensivo de arações e gradagens no sistema de plantio convencional (SPC), que potencializa as perdas de solo, água e nutrientes por erosão (PANACHUKI et al., 2011). Alternativamente ao SPC, o cultivo de cebola e de outras hortaliças tem sido realizado em sistema de plantio direto de hortaliças (SPDH), em que se utilizam plantas de cobertura, solteiras ou consorciadas, cujos resíduos são depositados na superfície do solo, sendo a mobilização do solo restrita à linha de plantio (KIELING et al., 2009).

Entre as espécies de plantas de cobertura de inverno mais utilizadas em SPDH destacam-se as gramíneas aveia-preta (Avena sativa L.) e centeio (Secale cereale L.), que produzem grandes quantidades de matéria seca (MS) e que, em geral, possuem elevada relação $\mathrm{C} / \mathrm{N}$, o que aumenta a persistência dos seus resíduos sobre a superfície do solo (EPAGRI, 2000). Em SPDH, a aveia-preta pode produzir $8 \mathrm{Mg}$ de $\mathrm{MS} \mathrm{ha}^{-1}$ e o centeio $4,5 \mathrm{Mg}$ de $\mathrm{MS} \mathrm{ha}^{-1}$. Mas as crucíferas, como o nabo-forrageiro (Raphanus sativus L.), também podem ser utilizadas no SPDH, principalmente por que possuem crescimento rápido, o que promove rápida cobertura do solo, produzindo, em média, $5 \mathrm{Mg}$ de MS ha $^{-1}$ (EPAGRI, 2000). O consórcio do nabo-forrageiro com uma gramínea pode proporcionar relação $\mathrm{C} / \mathrm{N}$ intermediária, possibilitando a cobertura da superfície do solo ao longo do tempo, mas também uma lenta decomposição dos resíduos e, por consequência, uma liberação gradual de nutrientes para o solo (GIACOMINI et al., 2003; CRUSCIOL et al., 2005).

Em SPDH, as plantas de cobertura, solteiras ou consorciadas podem absorver nutrientes em camadas profundas do solo e acumulá-los nas raízes ou na parte aérea, que, quando depositados na superfície do solo, podem liberar parte dos nutrientes contidos no tecido para o solo, alterando o teor de nutrientes nas camadas mais superficiais ao longo do ciclo da próxima cultura (PAULETTI et al., 2009). No caso particular da cebola, devido ao número reduzido de folhas e porte baixo, possui um menor índice de área foliar e o uso de espécies de plantas de cobertura é fundamental para que o SPDH seja iniciado com um alto aporte de resíduos, garantindo a cobertura do solo e viabilizando, inclusive, o aumento da produção de bulbos (CAMARGO, 2011).
O trabalho objetivou avaliar a interferência do cultivo e das quantidades de matéria seca de plantas de cobertura sobre a produção de cebola e os atributos químicos do solo, em sistema plantio direto agroecológico.

\section{MATERIAL E MÉTODOS}

Localização do experimento e tratamentos

O trabalho foi conduzido na Estação Experimental da Empresa de Pesquisa Agropecuária e Extensão Rural de Santa Catarina (EPAGRI), no município de Ituporanga, região do Alto Vale do Itajaí, Santa Catarina (SC) (Latitude $27^{\circ} 24^{\prime} 52^{\prime \prime}$, Longitude $49^{\circ}$ 36' 9"e altitude de $475 \mathrm{~m}$ ). O clima da região, segundo a classificação de Köeppen é subtropical mesotérmico úmido (Cfa), temperatura média anual de $17,6^{\circ} \mathrm{C}$ e precipitação anual média de $1.400 \mathrm{~mm}$. O solo foi classificado como Cambissolo Húmico e, na instalação do experimento, na camada de $0-10 \mathrm{~cm}$, apresentava: $380 \mathrm{~g} \mathrm{~kg}^{-1}$ de argila, $40 \mathrm{~g} \mathrm{~kg}^{-1}$ de matéria orgânica, $\mathrm{pH} \mathrm{em}$ água 6,2, Índice SMP 6,2; fósforo (P) disponível 26,6mg $\mathrm{dm}^{-3}$ e potássio (K) trocável $145,2 \mathrm{mg} \mathrm{dm}^{-3}$ (extraídos por Mehlich 1); alumínio (Al) trocável $0,0 \mathrm{cmol}_{\mathrm{c}} \mathrm{kg}^{-1}$, cálcio $(\mathrm{Ca})$ trocável $7,2 \mathrm{cmol}_{\mathrm{c}} \mathrm{kg}^{-1}$ e magnésio $(\mathrm{Mg})$ trocável 3,4 $\mathrm{cmol}_{\mathrm{c}} \mathrm{kg}^{-1}$ (extraídos por $\mathrm{KCl} 1 \mathrm{~mol} \mathrm{~L}^{-1}$ ); Capacidade de Troca de Cátions (CTC) 14,32 $\mathrm{cmol}_{\mathrm{c}} \mathrm{kg}^{-1}$, saturação da $\mathrm{CTC}_{\mathrm{pH} 7,0}$ por bases (V) 7,6\% e saturação da $\mathrm{CTC}_{\text {efetiva }}$ por alumínio $3,4 \mathrm{cmol}_{\mathrm{c}} \mathrm{kg}^{-1}$. $\mathrm{O}$ experimento foi instalado em uma área com histórico de cultivo convencional durante 30 anos. Em 1995, foi aplicado calcário na superfície do solo, com posterior incorporação, para elevar o pH em água até 6,0. No mesmo ano, foi adotado o SPD com rotação de culturas e o cultivo de plantas de cobertura. Em 2009, no momento da instalação do experimento, a vegetação espontânea foi dessecada, usando o herbicida glifosato. A partir de então, não foram mais utilizadas aplicações de agrotóxicos e fertilizantes minerais. Os tratamentos implantados foram: testemunha com vegetação espontânea (T1); aveia-preta (120kg ha-1 de semente) (T2); centeio (120kg ha-1 de semente) (T3); naboforrageiro (20 $\mathrm{kg} \mathrm{ha}^{-1}$ de semente) (T4); nabo-forrageiro $\left(10 \mathrm{~kg} \mathrm{ha}^{-1}\right.$ de semente $)+$ centeio $\left(60 \mathrm{~kg} \mathrm{ha}^{-1}\right.$ de semente) (T5); e nabo-forrageiro (10 kg ha-1 de semente) + aveiapreta (60kg ha ${ }^{-1}$ de semente) (T6). Em abril de $2010 \mathrm{e}$ 2011, as espécies de inverno foram novamente semeadas. No entanto, em abril de 2010, a aveia-preta dos tratamentos T2 e T6 foi substituída pela cevada (Hordeum vulgare L.) e, em abril de 2011, a cevada foi substituída pela aveia-preta novamente, em função da 
dificuldade em adquirir sementes de cevada. As espécies de inverno foram semeadas a lanço sobre a superfície do solo e, em seguida, uma máquina semeadora de cereais foi passada duas vezes na área. As quantidades de sementes por hectare foram calculadas com base nos valores mais elevados da recomendação de MONEGAT (1991) + 50\% . O delineamento experimental foi o de blocos ao acaso com oito repetições. Cada unidade experimental possuía $5 \mathrm{x} 5 \mathrm{~m}$, totalizando $25 \mathrm{~m}^{2}$.

Em julho de 2009, 2010 e 2011, todas as espécies de inverno foram acamadas, usando um rolofaca. Em seguida, foram aplicados na área $96 \mathrm{~kg} \mathrm{de} \mathrm{P}_{2} \mathrm{O}_{5}$ $\mathrm{ha}^{-1}$, na forma de fosfato natural de Gafsa, e $175 \mathrm{~kg}$ de $\mathrm{P}_{2} \mathrm{O}_{5} \mathrm{ha}^{-1}, 125 \mathrm{~kg}$ de $\mathrm{K}_{2} \mathrm{O} \mathrm{ha}^{-1}, 160 \mathrm{~kg} \mathrm{de} \mathrm{Nha}^{-1}$, na forma de dejetos de aves, metade aplicada no plantio das mudas e o restante 30 dias após o plantio. Na safra de 2011, não foi aplicado fosfato natural, pois os teores foram interpretados como muito alto. Posteriormente, foram abertos sulcos usando uma máquina de plantio direto e foram transplantadas manualmente as mudas de cebola, cv. 'Empasc 352' - Bola Precoce. O espaçamento usado foi $0,50 \mathrm{~m}$ nas entre linhas e $0,10 \mathrm{~m}$ entre plantas, com 10 linhas de cebola por parcela. Foram realizadas capinas aos 60 e 90 dias após o plantio das mudas (DAP) de cebola para diminuir o estande de plantas espontâneas. Em 2011, 30DAP foi realizada uma capina para o controle da aveia-preta, que rebrotou após o seu acamamento.

Avaliações, análises dos atributos químicos do solo e análise estatística

No presente trabalho, serão apresentados os resultados obtidos nos anos de 2010 e 2011 . Em maio, junho e julho de 2011, o que corresponde a 60, 80 e 95 dias após a semeadura (DAS) das espécies de plantas de cobertura, respectivamente, foram coletadas três subamostras de MS por parcela, usando um quadro de $0,5 \times 0,5 \mathrm{~m}\left(0,25 \mathrm{~m}^{2}\right)$. A massa verde foi armazenada, seca em estufa com ventilação de ar forçado a $65^{\circ} \mathrm{C}$ até peso constante e, $\log$ o depois, foi pesada para quantificar a produção de MS por hectare.

Em julho de 2010 e 2011, depois do acamamento das plantas de cobertura e antes da aplicação da fonte de $\mathrm{P}$ e do dejeto de aves, e, em dezembro de 2010 e 2011, depois da colheita da cebola, foi coletado solo na camada de $0-10 \mathrm{~cm}$. O solo foi seco, moído, passado em peneira com malha de $2 \mathrm{~mm}$ e submetido à análise de matéria orgânica; $\mathrm{pH}$ em água; $\mathrm{Ca}, \mathrm{Mg}$ e Al trocáveis (extraídos por $\mathrm{KCl} 1 \mathrm{~mol} \mathrm{~L}^{-1}$ ); $\mathrm{P}$ disponível e $\mathrm{K}$ trocável (extraídos por Mehlich 1)
(TEDESCO et al., 1995). Em seguida, foi calculada a $\mathrm{CTC}_{\mathrm{pH} 7,0}$ e a saturação da $\mathrm{CTC}_{\mathrm{pH} 7,0}$ por bases (CQFSRS/SC, 2004). Em novembro 2010 e 2011, foi realizada manualmente a colheita da cebola em oito linhas centrais de cada parcela e os bulbos permaneceram na superfície do solo por 10 dias para a cura (secagem e perda de água das folhas). Posteriormente, os bulbos foram pesados e classificados em calibres, de acordo com o HORTIBRASIL (2010): classe 0 (menor que $15 \mathrm{~mm}$ ); classe 1 (maior que 15 até $35 \mathrm{~mm}$ ), classe 2 (maior que 35 até $50 \mathrm{~mm}$ ); classe 3 (maior que 50 até $60 \mathrm{~mm}$ ); classe 4 (maior que 70 até $90 \mathrm{~mm}$ ); classe 5 (maior que $90 \mathrm{~mm}$ ) além dos bulbos com podridão e florescidos.

Os dados de produção de MS das plantas de cobertura de inverno, produção de cebola e atributos químicos do solo foram submetidos à análise de variância e, quando os efeitos foram significativos, as médias foram comparadas pelo teste de separação de médias Tukey a 5\% de probabilidade, utilizando-se o software Statistica $7^{\circ}$.

\section{RESULTADOS E DISCUSSÃO}

Produção de matéria seca das plantas de cobertura de inverno

O centeio (T3) e o nabo-forrageiro (T4) apresentaram a maior produção de MS da parte aérea aos 60 e 95DAS. A maior produção de MS aos 80DAS foi verificada no $\mathrm{T} 4$ e nos tratamentos consorciados, nabo-forrageiro + centeio (T5) e nabo-forrageiro + aveiapreta (T6). Entre as épocas de coleta, a maior produção de MS foi encontrada aos 80 e 95DAS em todos os tratamentos, em função da proximidade da época de acamamento. No entanto, no tratamento testemunha (T1), foi encontrada a menor produção de MS em todas as épocas de coleta, o que se refletiu na produção média.

A maior produção de MS da parte aérea do centeio (T3) ao longo das duas épocas de coleta (60 e 95DAS) pode ser atribuída ao seu sistema radicular profundo, que aumenta o volume de solo explorado pelas raízes e, por consequência, potencializa a absorção de nutrientes, a sua rusticidade, tolerância a condições adversas de cultivo, como, por exemplo, o estresse hídrico, e a sua alta capacidade de perfilhamento, o que se reflete na produção de MS. Já a elevada produção de MS do nabo-forrageiro (T4) aos 60 e 95 DAS pode ser explicada pelo seu rápido crescimento inicial e a intensa ramificação da parte aérea. Resultados semelhantes foram obtidos por VILANOVA (2011), que avaliou a produção da MS das 
mesmas espécies e no mesmo experimento do presente trabalho nas safras de 2009 e 2010. Esta autora relata que, na safra de 2009, a produção de MS do centeio foi de $5,0 \mathrm{Mg} \mathrm{ha}^{-1}$ e do nabo-forrageiro de $4,6 \mathrm{Mg} \mathrm{ha}^{-1}$. Já na safra de 2010, a produção do centeio foi de $3,0 \mathrm{Mg}$ de MS ha-1 e do nabo-forrageiro 4,2Mg de $\mathrm{MS} \mathrm{ha}^{-1}$. Do mesmo modo, GIACOMINI et al. (2003) avaliaram a produção de MS da parte aérea de cultivos solteiros e consorciados e observaram os maiores valores para o nabo-forrageiro solteiro, $5,0 \mathrm{Mg} \mathrm{ha} \mathrm{h}^{-1}$, que não diferiram de aveia-preta e ervilhaca. Porém, é de se esperar que, após a deposição dos resíduos das duas espécies de plantas de cobertura na superfície do solo, ocorrerá uma menor taxa de decomposição dos resíduos do centeio, comparativamente ao do nabo-forrageiro, principalmente devido ao maior teor de lignina e valor da relação $\mathrm{C} / \mathrm{N}$ e, com isso, haverá uma menor taxa de mineralização de nutrientes (HEINZ et al., 2010).

A menor produção de MS na testemunha (T1) ocorreu, provavelmente, porque, nesse tratamento, predominavam plantas espontâneas como a língua-devaca (Rumex obtusifolius), a orelha-de-urso (Stachys arvensis) e o caruru (Amaranthus lividus) (dados não apresentados), que possuem crescimento lento, refletindo em menor cobertura da superfície do solo e erosão em taxas mais elevadas (PANACHUKI et al., 2011).

Produção de cebola

$\mathrm{Na}$ safra de 2010, foram identificadas as classes de bulbos, 4, 3 e 2 . A produção de bulbos das classes 4 e 2 não diferiu entre os tratamentos, enquanto a maior produção de bulbos da classe 3 foi verificada nos tratamentos com espécies de plantas de cobertura. Em todos os tratamentos, foram encontrados bulbos podres ou florescidos, porém não se obtiveram diferenças significativas (Tabela 1).

$\mathrm{Na}$ safra de 2011, foram encontradas as classes de bulbos 3 e 2 . A maior produção de bulbos de cebola da classe 3 foi observada no tratamento com resíduos de aveia-preta (T2) e produções intermediárias foram encontradas com centeio (T3) e nabo-forrageiro (T4). A maior produção de bulbos da classe 2 foi obtida com o nabo-forrageiro (T4) e produções intermediárias com centeio (T3) e aveia-preta (T2). Em todos os tratamentos, foram verificados bulbos podres ou florescidos, sem que fossem verificadas diferenças significativas. A maior produção total de cebola foi encontrada nos tratamentos: nabo-forrageiro + aveia-

Tabela 1 - Produção de matéria seca de espécies de plantas de cobertura de inverno em 2011, produção de bulbos de cebola por classe comercial, bulbos com podridão e/ou florescido e produção total nas safras de 2010 e 2011.

\begin{tabular}{|c|c|c|c|c|c|c|c|c|c|}
\hline \multirow{2}{*}{ Tratamentos } & \multicolumn{3}{|c|}{--------Dias após a semeadura-------- } & \multirow{2}{*}{$\begin{array}{l}\text { Produção } \\
\text { média }\end{array}$} & \multirow[t]{2}{*}{ Classe 4} & \multirow[t]{2}{*}{ Classe 3} & \multirow[t]{2}{*}{ Classe 2} & \multirow{2}{*}{$\begin{array}{l}\text { Bulbos } \\
\text { Podridão/ } \\
\text { Florescido }\end{array}$} & \multirow[t]{2}{*}{ Total } \\
\hline & 60 & 80 & 95 & & & & & & \\
\hline \multicolumn{10}{|c|}{ 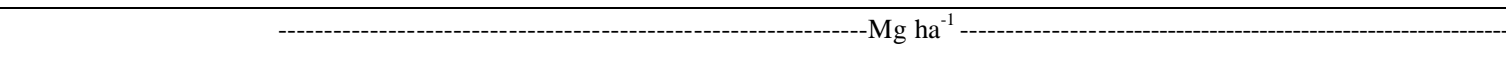 } \\
\hline T1-Testemunha $^{(1)}$ & - & - & - & - & $0,1 \mathrm{a}^{(2)}$ & $2,1 \mathrm{~b}$ & $7,3 \mathrm{a}$ & $0,1 \mathrm{a}$ & $9,5 \mathrm{~b}$ \\
\hline T2-Cevada & - & - & - & - & $0,1 \mathrm{a}$ & $5,2 \mathrm{a}$ & $7,3 \mathrm{a}$ & $0,2 \mathrm{a}$ & $12,6 \mathrm{a}$ \\
\hline T3-Centeio & - & - & - & - & $0,3 \mathrm{a}$ & $4,8 \mathrm{a}$ & $6,4 \mathrm{a}$ & $0,5 \mathrm{a}$ & $12,5 \mathrm{a}$ \\
\hline T4-Nabo-forrageiro & - & - & - & - & $0,3 \mathrm{a}$ & $5,7 \mathrm{a}$ & $7,0 \mathrm{a}$ & $0,5 \mathrm{a}$ & $13,5 \mathrm{a}$ \\
\hline T5-Nabo+Centeio & - & - & - & - & $0,2 \mathrm{a}$ & $6,2 \mathrm{a}$ & $6,7 \mathrm{a}$ & $0,2 \mathrm{a}$ & $13,4 \mathrm{a}$ \\
\hline T6-Nabo+Cevada & - & - & - & - & $0,3 \mathrm{a}$ & $5,0 \mathrm{a}$ & $7,7 \mathrm{a}$ & $0,4 \mathrm{a}$ & $13,2 \mathrm{a}$ \\
\hline T1-Testemunha & $0,7 \mathrm{cA}$ & $0,9 \mathrm{cA}$ & $0,8 \mathrm{cA}$ & $0,8 \mathrm{~b}$ & - & $0,7 \mathrm{~d}$ & $10,1 \mathrm{c}$ & $0,1 \mathrm{a}$ & $10,8 \mathrm{c}$ \\
\hline T2-Aveia-preta & $2,0 \mathrm{abB}$ & $3,0 \mathrm{abA}$ & $3,3 \mathrm{abA}$ & $2,8 \mathrm{a}$ & - & $6,6 \mathrm{a}$ & $11,5 \mathrm{~b}$ & $0,2 \mathrm{a}$ & $18,3 \mathrm{a}$ \\
\hline T3-Centeio & $2,2 \mathrm{aB}$ & $2,8 \mathrm{bA}$ & $3,4 \mathrm{aA}$ & $2,8 \mathrm{a}$ & - & $4,5 \mathrm{bc}$ & $12,0 \mathrm{~b}$ & $0,1 \mathrm{a}$ & $16,6 \mathrm{~b}$ \\
\hline T4-Nabo-forrageiro & $2,2 \mathrm{aB}$ & $3,2 \mathrm{aA}$ & $3,5 \mathrm{aA}$ & $3,0 \mathrm{a}$ & - & $3,7 \mathrm{c}$ & $13,2 \mathrm{a}$ & $0,3 \mathrm{a}$ & $17,2 \mathrm{ab}$ \\
\hline T5-Nabo+Centeio & $1,9 \mathrm{abB}$ & $3,3 \mathrm{aA}$ & $3,3 \mathrm{abA}$ & $2,9 \mathrm{a}$ & - & $5,1 \mathrm{abc}$ & $12,3 \mathrm{ab}$ & $0,2 \mathrm{a}$ & $17,6 \mathrm{ab}$ \\
\hline T6-Nabo+Aveia & $1,7 \mathrm{bB}$ & $3,3 \mathrm{aA}$ & $3,0 \mathrm{bA}$ & $2,7 \mathrm{a}$ & - & $6,0 \mathrm{ab}$ & $12,4 \mathrm{ab}$ & $0,1 \mathrm{a}$ & $18,4 \mathrm{a}$ \\
\hline
\end{tabular}

${ }^{(1)}$ Vegetação espontânea. ${ }^{(2)}$ Médias seguidas pela mesma letra minúscula na coluna e maiúscula na linha não diferem entre si pelo teste Tukey, a 5\% de probabilidade. 
preta (T6) e aveia-preta (T2). Por outro lado, a menor produção total e das classes 2 e 3 foi verificada com a testemunha (T1), a exemplo dos dados obtidos na safra de 2010 (Tabela 1).

A maior produção total de cebola e da classe 3 na safra de 2010 em todos os tratamentos com resíduos de espécies de plantas de cobertura de inverno, comparativamente ao tratamento testemunha (T1), pode ser explicado pela maior produção de MS, que aumenta a proteção da superfície do solo contra o impacto da gota da chuva, o que, por consequência, diminui a perda de solo, água e nutrientes por escoamento superficial (PANACHUKI et al., 2011), e também pela ciclagem de nutrientes, uma vez que os resíduos na superfície do solo em decomposição liberam nutrientes (PACHECO et al., 2011) e parte deles pode ser absorvida pela cebola ao longo do seu ciclo. Já a menor produção total de cebola e da classe 3 na testemunha (T1) pode ser atribuída à presença das plantas espontâneas que pouco protegem a superfície do solo, mas também à competição delas com a cebola, especialmente, por água e nutrientes (VILANOVA, 2011). Isso é comprovado por SOARES et al. (2003), os quais comentam que a convivência da cebola com plantas espontâneas durante os primeiros 98 dias reduziu a produção em 95\% e o peso médio de bulbos em $91 \%$.

Além disso, a maior produção de cebola no solo dos tratamentos com resíduos de aveia-preta (T2) e nabo-forrageiro + aveia-preta (T6) pode ser atribuída à maior quantidade de $\mathrm{Ne} \mathrm{P}$ acumulada na parte aérea do nabo-forrageiro e à sua rápida liberação, quando os resíduos estiverem em decomposição na superfície do solo (HEINZ et al., 2011), contribuindo para a nutrição da cebola. Já a aveia-preta absorve quantidades de K das camadas mais profundas do solo acima de sua demanda, acumulando-o na parte aérea em organelas como o vacúolo, o que caracteriza o consumo de luxo (BRUNETTO et al., 2005), que será liberado lentamente durante o ciclo da cebola, se comparado ao naboforrageiro (CRUSCIOL et al., 2005).

A produção total de cebola na safra de 2011 foi maior que a observada na safra de 2010 , o que pode ser atribuído à presença das plantas de cobertura em SPDH e, por consequência, à proteção da superfície do solo, o que pode contribuir para a manutenção dos teores de nutrientes.

\section{Atributos químicos}

Os teores de matéria orgânica, $\mathrm{pH}$ em água, Ca trocável, $\mathrm{Mg}$ trocável, $\mathrm{Al}$ trocável, $\mathrm{P}$ disponível e $\mathrm{CTC}_{\mathrm{pH} 7,0}$ no solo da camada de $0-10 \mathrm{~cm}$, após o acamamento das plantas de cobertura de inverno e a colheita da cebola nas safras de 2010 e 2011 não foram afetados pelo cultivo de plantas de cobertura, nem pela deposição dos seus resíduos (Tabela 2). Na safra de 2010 , os teores de K trocável no solo foram maiores no consórcio nabo-forrageiro + cevada após o acamamento das plantas de cobertura de inverno e após a colheita da cebola. Isso pode ser explicado, provavelmente, pela grande quantidade de K absorvida do solo e, por consequência, sua acumulação nos tecidos das duas espécies, que, quando em contato com o solo, serão decompostos, proporcionando a liberação dos nutrientes (PACHECO et al., 2011). Os maiores teores de $\mathrm{K}$ trocável no solo com resíduos de nabo-forrageiro contribuíram para o incremento do valor de soma de bases, refletindo em maiores valores da saturação da $\mathrm{CTC}_{\mathrm{pH} 7,0}$ por bases (Tabela 2).

Nas safras de 2010 e 2011, em todos os tratamentos, os teores de $\mathrm{K}$ trocável e $\mathrm{P}$ disponível no solo foram maiores após a colheita da cebola, comparativamente aos teores observados após o acamamento das plantas de cobertura de inverno (Tabela 2). Esses resultados podem, em parte, ser atribuídos à adubação com dejetos de aves e à aplicação de P nas linhas de plantio da cebola, logo após o acamamento das plantas de cobertura de inverno. Ademais, as plantas de cobertura são eficientes na ciclagem dos nutrientes por explorar diversas camadas do solo, proteger a superfície do impacto das gotas da chuva, reduzir variações de temperatura e manter a umidade, contribuindo para a manutenção e/ ou aumento da fertilidade do solo (MELO et al., 2011). Os teores de $\mathrm{P}$ disponível, de $\mathrm{K}$ trocável, de Ca trocável e Mg trocável em todos os tratamentos e nas duas safras foram interpretados como alto, enquanto que os valores de $\mathrm{pH}$ em água e de saturação da $\mathrm{CTC}_{\mathrm{pH} 7,0}$ por bases foram interpretados como médio. Já os valores de $\mathrm{CTC}_{\mathrm{pH} 700} \mathrm{em}$ todos os tratamentos, na safra de 2010, foram interpretados como médio e na safra de 2011 como alto (CQFS-RS/SC, 2004).

\section{CONCLUSÃO}

O cultivo e a deposição dos resíduos de matéria seca das espécies de plantas de cobertura em sistema plantio direto contribuíram para o aumento e a manutenção da produção total de cebola ao longo dos anos. Os atributos químicos do solo, com exceção do potássio trocável, fósforo disponível e valores de saturação da $\mathrm{CTC}_{\mathrm{pH} 7,0}$ por bases, não foram afetados pelo cultivo com espécies de plantas de cobertura solteiras e consorciadas. 
Tabela 2 - Teores de matéria orgânica, valores de pH em água, teores de cálcio trocável, magnésio trocável, alumínio trocável, potássio trocável, fósforo disponível e saturação da $\mathrm{CTC}_{\mathrm{pH} 7,0}$ por bases $(\mathrm{V})$ na camada de $0-10 \mathrm{~cm}$, em um solo Cambissolo Húmico, submetido ao cultivo de espécies de plantas de cobertura solteiras e consorciadas, em sistema plantio direto agroecológico de cebola.

\begin{tabular}{|c|c|c|c|c|c|c|c|c|c|}
\hline Tratamentos & $\begin{array}{c}\text { Matéria } \\
\text { orgânica } \\
\%\end{array}$ & $\begin{array}{l}\mathrm{pH} \text { em } \\
\text { água }\end{array}$ & - & $\mathrm{mol}_{\mathrm{c}} \mathrm{kg}$ & - & ---------m & $n^{-3}----------$ & $\begin{array}{l}\mathrm{CTC}_{\mathrm{pH} 7,0} \\
\mathrm{cmol}_{\mathrm{c}} \mathrm{kg}^{-1}\end{array}$ & $\mathrm{~V} \%$ \\
\hline \multicolumn{10}{|c|}{ 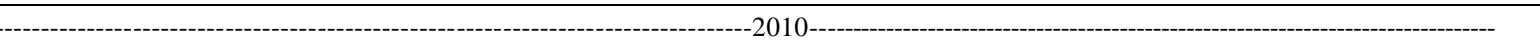 } \\
\hline T1-Testemunha $^{(1)}$ & $3,3 \mathrm{aA}^{(2)}$ & $5,8 \mathrm{aA}$ & $5,7 \mathrm{aA}$ & $2,9 \mathrm{aA}$ & $0,0 \mathrm{aA}$ & $58,9 \mathrm{aA}$ & $406,8 \mathrm{abA}$ & $14,1 \mathrm{aA}$ & $66,7 \mathrm{aA}$ \\
\hline T2-Cevada & $3,2 \mathrm{aA}$ & $5,7 \mathrm{aA}$ & $5,4 \mathrm{aA}$ & $2,7 \mathrm{aA}$ & $0,0 \mathrm{aA}$ & $59,1 \mathrm{aA}$ & $339,8 \mathrm{bB}$ & $13,8 \mathrm{aA}$ & $65,5 \mathrm{aA}$ \\
\hline T3-Centeio & $3,3 \mathrm{aA}$ & $5,8 \mathrm{aA}$ & $5,9 \mathrm{aA}$ & $2,8 \mathrm{aA}$ & $0,0 \mathrm{aA}$ & $52,9 \mathrm{aB}$ & $405,3 \mathrm{abB}$ & $14,6 \mathrm{aA}$ & $66,6 \mathrm{aA}$ \\
\hline T4-Nabo-forrageiro & $3,4 \mathrm{aA}$ & $5,8 \mathrm{aA}$ & $5,9 \mathrm{aA}$ & $2,7 \mathrm{aA}$ & $0,0 \mathrm{aA}$ & $58,9 \mathrm{aB}$ & $412,3 \mathrm{abB}$ & $14,3 \mathrm{aA}$ & $67,5 \mathrm{aA}$ \\
\hline T5-Nabo+Centeio & $3,3 \mathrm{aA}$ & $5,7 \mathrm{aA}$ & $5,9 \mathrm{aA}$ & $2,7 \mathrm{aA}$ & $0,0 \mathrm{aA}$ & $50,3 \mathrm{aB}$ & $382,5 \mathrm{abB}$ & $14,3 \mathrm{aA}$ & $66,7 \mathrm{aA}$ \\
\hline T6-Nabo+Cevada & $3,3 \mathrm{aA}$ & $5,9 \mathrm{aA}$ & $5,8 \mathrm{aA}$ & $2,9 \mathrm{aA}$ & $0,0 \mathrm{aA}$ & $58,5 \mathrm{aB}$ & $464,0 \mathrm{aB}$ & $14,4 \mathrm{aA}$ & $68,6 \mathrm{aA}$ \\
\hline T1-Testemunha & $4,0 \mathrm{aA}$ & $5,6 \mathrm{aA}$ & $5,5 \mathrm{aA}$ & $\begin{array}{c}s \text { a colhe } \\
3,1 \mathrm{aA}\end{array}$ & $\begin{array}{c}\text { da cebol } \\
0,0 \mathrm{aA}\end{array}$ & $62,3 \mathrm{aA}$ & $468,5 \mathrm{abA}$ & $14,8 \mathrm{aA}$ & 65,9abA \\
\hline T2-Cevada & $4,1 \mathrm{aA}$ & $5,5 \mathrm{aA}$ & $5,4 \mathrm{aA}$ & $3,0 \mathrm{aA}$ & $0,0 \mathrm{aA}$ & $68,9 \mathrm{aA}$ & $449,0 \mathrm{bA}$ & $14,6 \mathrm{aA}$ & $65,2 \mathrm{bA}$ \\
\hline T3-Centeio & $4,1 \mathrm{aA}$ & $5,7 \mathrm{aA}$ & $5,6 \mathrm{aA}$ & $3,2 \mathrm{aA}$ & $0,0 \mathrm{aA}$ & $72,5 \mathrm{aA}$ & $517,5 \mathrm{abA}$ & $14,8 \mathrm{aA}$ & $67,8 \mathrm{abA}$ \\
\hline T4-Nabo-forrageiro & $4,0 \mathrm{aA}$ & $5,8 \mathrm{aA}$ & $5,7 \mathrm{aA}$ & $3,3 \mathrm{aA}$ & $0,0 \mathrm{aA}$ & $73,3 \mathrm{aA}$ & $524,5 \mathrm{abA}$ & $14,8 \mathrm{aA}$ & $69,6 \mathrm{aA}$ \\
\hline T5-Nabo+Centeio & $4,3 \mathrm{aA}$ & $5,6 \mathrm{aA}$ & $5,7 \mathrm{aA}$ & $3,3 \mathrm{aA}$ & $0,0 \mathrm{aA}$ & $98,1 \mathrm{aA}$ & $502,5 \mathrm{abA}$ & $15,5 \mathrm{aA}$ & $66,3 \mathrm{abA}$ \\
\hline T6-Nabo+Cevada & $4,0 \mathrm{aA}$ & $5,7 \mathrm{aA}$ & $5,6 \mathrm{aA}$ & $3,3 \mathrm{aA}$ & $0,0 \mathrm{aA}$ & $70,1 \mathrm{aA}$ & $527,5 \mathrm{aA}$ & $15,0 \mathrm{aA}$ & $68,6 \mathrm{abA}$ \\
\hline T1-Testemunha & $3,4 \mathrm{aA}$ & $5,3 \mathrm{aA}$ & $\begin{array}{c}\mathrm{o} \text { acama } \\
5,5 \mathrm{aA}\end{array}$ & $3,2 \mathrm{aA}$ & $\begin{array}{r}\text { tas de cr } \\
0,0 \mathrm{aA}\end{array}$ & $\begin{array}{c}\text { ura de inv } \\
28,3 \mathrm{aB}\end{array}$ & $341,0 \mathrm{aB}$ & $15,2 \mathrm{aA}$ & $62,7 \mathrm{aB}$ \\
\hline T2-Aveia-preta & $3,5 \mathrm{aA}$ & $5,4 \mathrm{aA}$ & $5,7 \mathrm{aA}$ & $3,5 \mathrm{aA}$ & $0,0 \mathrm{aA}$ & $34,0 \mathrm{aB}$ & $304,0 \mathrm{aB}$ & $16,3 \mathrm{aA}$ & $61,7 \mathrm{aA}$ \\
\hline T3-Centeio & $3,5 \mathrm{aA}$ & $5,5 \mathrm{aA}$ & $5,8 \mathrm{aA}$ & $3,2 \mathrm{aA}$ & $0,0 \mathrm{aA}$ & $37,0 \mathrm{aB}$ & $311,5 \mathrm{aB}$ & $16,3 \mathrm{aA}$ & $59,5 \mathrm{aB}$ \\
\hline T4-Nabo-forrageiro & $3,5 \mathrm{aA}$ & $5,5 \mathrm{aA}$ & $6,0 \mathrm{aA}$ & $3,5 \mathrm{aA}$ & $0,0 \mathrm{aA}$ & $37,5 \mathrm{aB}$ & $315,0 \mathrm{aB}$ & $15,5 \mathrm{aA}$ & $66,4 \mathrm{aB}$ \\
\hline T5-Nabo+Centeio & $3,4 \mathrm{aA}$ & $5,5 \mathrm{aA}$ & $6,1 \mathrm{aA}$ & $3,5 \mathrm{aA}$ & $0,0 \mathrm{aA}$ & $33,3 \mathrm{aB}$ & $337,5 \mathrm{aB}$ & $16,1 \mathrm{aA}$ & $64,8 \mathrm{aB}$ \\
\hline T6-Nabo+Aveia & $3,3 \mathrm{aA}$ & $5,5 \mathrm{aA}$ & $5,7 \mathrm{aA}$ & $3,1 \mathrm{aA}$ & $0,0 \mathrm{aA}$ & $36,7 \mathrm{aB}$ & $307,5 \mathrm{aB}$ & $15,7 \mathrm{aA}$ & $61,6 \mathrm{aB}$ \\
\hline T1-Testemunha & $3,6 \mathrm{aA}$ & $5,7 \mathrm{aA}$ & $6,5 \mathrm{aA}$ & $\begin{array}{c}\text { pós a co } \\
3,8 \mathrm{aA}\end{array}$ & $\begin{array}{c}\text { ta da ce } \\
0,0 \mathrm{aA}\end{array}$ & $47,2 \mathrm{aA}$ & $437,0 \mathrm{aA}$ & $15,9 \mathrm{aA}$ & $71,4 \mathrm{aA}$ \\
\hline T2-Aveia-preta & $3,5 \mathrm{aA}$ & $5,6 \mathrm{aA}$ & $5,9 \mathrm{aA}$ & $3,3 \mathrm{aA}$ & $0,0 \mathrm{aA}$ & $50,8 \mathrm{aA}$ & $385,3 \mathrm{aA}$ & $14,7 \mathrm{aA}$ & $67,4 \mathrm{aA}$ \\
\hline T3-Centeio & $3,5 \mathrm{aA}$ & $5,6 \mathrm{aA}$ & $6,4 \mathrm{aA}$ & $3,6 \mathrm{aA}$ & $0,0 \mathrm{aA}$ & $46,8 \mathrm{aA}$ & $425,8 \mathrm{aA}$ & $15,7 \mathrm{aA}$ & $70,3 \mathrm{aA}$ \\
\hline T4-Nabo-forrageiro & $3,7 \mathrm{aA}$ & $5,7 \mathrm{aA}$ & $7,1 \mathrm{aA}$ & $3,9 \mathrm{aA}$ & $0,0 \mathrm{aA}$ & $46,0 \mathrm{aA}$ & $417,3 \mathrm{aA}$ & $16,2 \mathrm{aA}$ & $74,2 \mathrm{aA}$ \\
\hline T5-Nabo+Centeio & $3,7 \mathrm{aA}$ & $5,6 \mathrm{aA}$ & $6,9 \mathrm{aA}$ & $4,0 \mathrm{aA}$ & $0,0 \mathrm{aA}$ & $45,1 \mathrm{aA}$ & $418,5 \mathrm{aA}$ & $16,5 \mathrm{aA}$ & $72,0 \mathrm{aA}$ \\
\hline T6-Nabo+Aveia & $3,7 \mathrm{aA}$ & $5,7 \mathrm{aA}$ & $7,0 \mathrm{aA}$ & $3,8 \mathrm{aA}$ & $0,0 \mathrm{aA}$ & $47,5 \mathrm{aA}$ & $405,0 \mathrm{aA}$ & $16,1 \mathrm{aA}$ & $73,4 \mathrm{aA}$ \\
\hline
\end{tabular}

(1) testemunha = vegetação espontânea; ${ }^{(2)}$ Médias seguidas pela mesma letra minúscula (entre tratamentos) e maiúscula (entre épocas) na coluna não diferem entre si pelo teste de Tukey, a 5\% de probabilidade.

\section{AGRADECIMENTOS}

Ao Conselho Nacional de Desenvolvimento Científico e Tecnológico (CNPq) pela concessão da bolsa e ao MDA/SAF/CNPq - Edital n.58/2010 e à Fundação de Amparo à Pesquisa e Inovação do Estado de Santa Catarina (FAPESC), Edital Ciências Agrárias - FAPESC - 08/2009, pelo auxílio financeiro.

\section{REFERÊNCIAS}

BRUNETTO, G. et al. Nível crítico e resposta das culturas ao potássio em um Argissolo sob sistema plantio direto. Revista Brasileira Ciência do Solo, v.29, n.4, p.565-571, 2005. Disponível em: <http://dx.doi.org/10.1590/S0100-0683200
5000400009>. Acesso em: 21 mar. 2012. doi: 10.1590/S010006832005000400009 .

CAMARGO, E.S. Manejo conservacionista do solo e rotação de culturas para cebola. 2011. 80f. Dissertação (Mestrado em Manejo do Solo) - Programa de Pós-graduação em Ciências Agrárias, Universidade do Estado de Santa Catarina, Lages, SC.

COMISSÃO DE QUÍMICA E FERTILIDADE DO SOLO - RS/ SC. Manual de adubação e calagem para os Estados do Rio Grande do Sul e de Santa Catarina. 10. ed. Porto Alegre: SBCS - Núcleo Regional Sul/UFRGS, 2004. 400p. 
CRUSCIOL, C.A. et al. Persistência de palhada e liberação de nutrientes do nabo-forrageiro no plantio direto. Pesquisa Agropecuária Brasileira, v.40, n.2, p.161-168, 2005. Disponível em: <http://dx.doi.org/10.1590/S0100-204X20050 00200009>. Acesso em: 23 dez. 2011. doi: 10.1590/S0100204X2005000200009.

EPAGRI. Sistema de produção para cebola: Santa Catarina. Florianópolis, 2000. 91p. (Epagri. Sistemas de Produção, 16).

GIACOMINI, S.J. et al. Matéria seca, relação C/N e acúmulo de nitrogênio, fósforo e potássio em misturas de plantas de cobertura de solo. Revista Brasileira Ciência do Solo, v.27, n.2, p.325-334, 2003. Disponível em: <http://dx.doi.org/ 10.1590/S0100-06832003000200012>. Acesso em: $23 \mathrm{dez}$. 2012. doi: 10.1590/S0100-06832003000200012.

HEINZ, F. et al. Decomposição e liberação de nutrientes de resíduos culturais de crambe e nabo forrageiro. Ciência Rural, v.41, n.9, p.1549-1555, 2010. Disponível em: <http:// dx.doi.org/10.1590/S0103-84782011000900010>. Acesso em: 19 mar. 2012. doi: 10.1590/S0103-84782011000900010.

HORTIBRASIL - Instituto Brasileiro de Qualidade em Horticultura. Norma de classificação da cebola. Acesso em: 20 jul. 2010. Online. Disponível em: <http:// www.hortibrasil.org.br/classificacao/cebola/arquivos/ norma.html>.

KIELING, A.S. et al. Plantas de cobertura de inverno em sistema plantio direto de hortaliças sem herbicidas: efeitos sobre plantas espontâneas e na produção de tomate. Ciência Rural, v.39, n.7, p.2207-2209, 2009. Disponível em: <http://dx.doi.org/ 10.1590/S0103-84782009000700040>. Acesso em: 01 mar. 2012. doi: $10.1590 / \mathrm{S} 0103-84782009000700040$.

MELO, A.V. et al. Extração de nutrientes e produção de biomassa de aveia-preta cultivada em solo submetido a dezoito anos de adubação orgânica e mineral. Semina: Ciências Agrárias, v.32, n.2, p.411-420, 2011. Disponível em: <http://www.uel.br/ revistas/uel/index.php/semagrarias/article/view/3113>. Acesso em: 14 ago. 2012. doi: 10.5433/1679-0359.2011v32n2p411.
MONEGAT, C. Plantas de cobertura do solo: características e manejo em pequenas propriedades. Chapecó: [Edição do autor], 1991. 336p.

PACHECO, L.P. et al. Produção de fitomassa e acúmulo e liberação de nutrientes por plantas de cobertura na safrinha. Pesquisa Agropecuária Brasileira, v.46, n.1, p.17-25, 2011. Disponível em: <http://dx.doi.org/10.1590/S0100-204X2011 000100003>. Acesso em: 15 mar. 2012. doi: 10.1590/S0100204X2011000100003.

PANACHUKI, E. et al. Perdas de solo e de água e infiltração de água em latossolo vermelho sob sistemas de manejo. Revista Brasileira Ciência do Solo, v.35, p.1777-1785, 2011. Disponível em: <http://dx.doi.org/10.1590/S0100-06832011 000500032>. Acesso em: 15 mar. 2012. doi: 10.1590/S010006832011000500032 .

PAUletTI, V. et al. Atributos químicos de um Latossolo bruno sob sistema plantio direto em função da estratégia de adubação e do método de amostragem de solo. Revista Brasileira de Ciência do Solo, v.33, p.581-590, 2009. Disponível em: <http://dx.doi.org/10.1590/S0100-06832009 000300011>. Acesso em: 18 jan. 2012. doi: 10.1590/S010006832009000300011 .

SOARES, D.J. et al. Períodos de interferência das plantas daninhas na cultura de cebola (Allium cepa) transplantada. Planta Daninha, v.21, n.3, p.387-396, 2003. Disponível em: 〈http://dx.doi.org/10.1590/S0100-83582003000300006>. Acesso em: 27 ago. 2011. doi: 10.1590/S010083582003000300006 .

TEDESCO, M.J. et al. Análises de solos, plantas e outros materiais. 2.ed. Porto Alegre: Departamento de Solos da Faculdade de Agronomia, 1995. 174p. (Boletim Técnico, 5).

VILANOVA, C.C. Sistema de plantio direto de cebola: contribuições das plantas de cobertura no manejo ecológico de plantas espontâneas. 2011. 76f. Dissertação (Mestrado em Agroecossistemas) - Programa de Pós-graduação em Agroecossistemas, Universidade Federal de Santa Catarina, SC. 